\title{
Modular argumentation for modelling legal doctrines of performance relief
}

\author{
Phan Minh Dung*, Phan Minh Thang and Nguyen Duy Hung \\ Department of Computer Science, Asian Institute of Technology, GPO Box 4, Klong Luang, \\ Pathumthani 12120, Thailand
}

(Received 22 August 2009; final version received 16 December 2009)

\begin{abstract}
We present an argument-based formalism of contract dispute resolution following a modern view that the court would resolve a contract dispute by enforcing an interpretation of contract that reasonably represents the mutual intention of contract parties. Legal doctrines provide principles, rules and guidelines for the court to objectively arrive at such an interpretation. In this paper, we establish the appropriateness of the formalism by applying it to resolve disputes about performance relief with the legal doctrines of impossibility and frustration of purpose in common laws of contract. The formalism is based on modular argumentation, a recently proposed extension of assumption-based argumentation for modelling contract dispute resolution.
\end{abstract}

Keywords: legal doctrines; impossibility; frustration of purpose; dispute resolution; modular argumentation

\section{Introduction}

The freedom of contract making leads us to believe that a contract is signed only if it benefits both contract parties. However, no contract could contain clauses for every eventuality since contract parties simply could not foresee all possible events in a dynamic world, or simply decide not to raise them during negotiations, as their expected utilities are considered of low value. Subsequently, parties have incentive to repudiate when they suffer losses because of such events, with arguments that sound like 'I did not promise to perform under these changed circumstances'.

Commerce is not possible without the commitment of contract parties to their signed contracts, which would be undermined if it was possible for a party to enjoy the fruits of the contract from the performance of the other party without having to perform his own promise. Thus contract dispute resolution is indispensable in any commercial world. E-commerce demands online arbitration because dispute resolution in courts is costly if not impossible, especially when parties to online contracts are separated geographically. Online arbitration mechanisms would hence be of great importance for a take-off of e-commerce.

To understand how online arbitration mechanisms could be designed, we need to understand how courts resolve contract disputes because real-world contract dispute resolution must be guided by laws, even if such disputes may be resolved by bodies other than the court of laws. Consider a famous court case below (Farnsworth, Young, and Sanger 2001; Freitel 2004).

Example 1.1 (Taylor v Caldwell, 1863) Taylor hired Caldwell's hall for the purpose of giving four grand concerts. Taylor were to pay $£ 100$ in the evening of each concert. After signing the

${ }^{*}$ Corresponding author. Email: dung@cs.ait.ac.th 
contract but before the first concert, a fire destroyed the hall. Taylor claimed damages ( $£ 58$ ) in respect of the expenses which Taylor had incurred in advertising and preparing for the concerts. The claim was dismissed for the reason that the fire, an unexpected event for both parties, destroyed the hall, the non-existence of which renders the performance of contract impossible. Thus both parties are discharged. Taylor was not entitled to damages, while Caldwell was not entitled to the promised payment.

Contract disputes, in an abstract sense, could be viewed as argumentation about contract interpretation whereby contract parties present arguments for or against a particular interpretation they wish to advance or reject, respectively. This paper, an extension of Dung, Thang, and Hung (2009), presents a contract dispute resolution formalism following a modern view that the court would resolve a contract dispute by enforcing a hypothetical contract (also called complete intended contract) that reasonably represents the mutual intention of contract parties at the time of contract making. The court assumes that both parties are rational in order to equate their mutual intention with the intention of rational persons in the position with all their background (or contextual) knowledge. Because an actual contract is often viewed as representing the clearest mutual intention of contract parties, a hypothetical contract does not rewrite explicit contractual terms, instead adds implied terms representing the shared, but unexpressed intention of contract parties. To ascertain this intention objectively, the court generally applies well-established legal principles, guidelines and rules. Thus a dispute resolution is modelled here by a two-level modular argumentation (Dung and Thang 2008, 2009) process: at the object level, factors of the case are established from argumentation modules representing the contract context while at the meta-level, argumentation modules representing such legal principles and rules combine these factors to complete the actual contract with implied terms.

We establish the appropriateness of the above formalism by applying it to common laws. Having a case-by-case basis, however common laws generally evolve by distilling from a particular case the legal principle on which it is decided, and that legal principle is then generally applied to similar dispute contexts (Samuel 2000). Legal doctrines in common laws could be viewed as a widely accepted interpretations of the principles, guidelines and rules for dispute resolution. In this paper, we will formally model legal doctrines for resolving disputes on performance relief (i.e. where a contract has been signed but one party asks to rescind the contract) in Restatement Second of Contracts, especially the doctrines of impossibility and frustration of purpose. These two doctrines provide, on one hand, arguments for rescission on the grounds that an unexpected event after the contract making has made the performance of the contract literally impossible, or destroyed the principal goal of a party in entering into the contract; and on the other hand, arguments against rescission on grounds that parties bearing the risk of the event by explicit or implied terms in the complete intended contract cannot withdraw from the contract when the risk materialises. For illustration, consider the hypothetical e-commerce disputes below.

Example 1.2 A GIS company has a contract with a fishing company to map fish-rich areas around a sea port from images of Landsat satellites. The GIS company uses images of Landsat 7, but after the contract signing, the Scan Line Corrector of this satellite fails unexpectedly, causing about $22 \%$ of any scene to be lost. ${ }^{1}$ The supplied map hence blanks out a significant part. Without reliable information about the fishing ground, the fishing company suffers a bad season. It sues the GIS company.

The GIS company asks for relief of performance, citing the doctrine of impossibility, on grounds that it cannot render the contracted service at areas that are not imaged by Landsat 7 . 
The fishing company argues that the GIS company, being an expert in Remote Sensing, should be able to foresee that Landsat 7 could function improperly. Thus, the GIS company should have improved its mapping algorithms, e.g. by using extra data sources, so that in the current situation it could still render its service satisfactorily. The failure to do so allocates the risk to the GIS company.

Example 1.3 Consider the same contract but this time an oil spill occurred, reducing the fish potential so significantly that fishing is clearly not beneficial. The fishing company did not fish and refuses to pay. The GIS company sues. The fishing company asks for relief of performance, citing the doctrine of frustration of purpose, because its principal goal in entering into contract (i.e. fishing) is substantially frustrated by the oil spill.

The doctrine of impossibility is one of the most important doctrines of contract laws. On the one hand, by defining an extremely narrow gap for a non-performance of a contractual promise not to be deemed as a contract breach, the doctrine makes it 'almost impossible' or 'practically impossible' for contract parties to break their contractual promises. On the other hand, by discharging contracts in truly impossible situations, the doctrine avoids causing extra distress to contract parties in a situation beyond their capacity to handle, and hence supports the view that commerce is to increase the wealth of a society. In our related paper (Dung and Thang 2009), we have modelled the doctrine of mutual mistake, which provides arguments for rescission on grounds that a mistake concerning an existing fact made by both parties at the time of contract making nullifies what parties intended to agree on; and arguments against rescission on the grounds of risk allocation of this type of mistake. The fact that our formalism can naturally model several complicated legal doctrines shows our initial success towards a simple yet general argument-based formalism for contract dispute resolution. For each doctrine, we need to refine the semantics of contract by defining what kinds of implied terms the doctrine imports, and formulate the above two-level argumentation process to compute the semantics. Since each doctrine has its own peculiarities, moreover can be made or unmade by courts, we cannot make a definite claim as to the completeness of the presented formalism. Instead, we can only establish its appropriateness by its successive application to relevant doctrines. The more natural this application is, the more appropriate the formalism is.

To our best knowledge, there has not been sufficient work focusing on contract interpretation. Exceptions are the formalism of Yoshino $(1995,1998)$ using meta-level rules in first-order logic to deduce contractual obligations, and the rule-based system of Gardner (1987) supporting decision makers, both in the offer-and-acceptance area of contract. In general, these formalisms do not model possible outcomes of contract dispute resolution since they are silent on important aspects, for example, how contexts are structured or how to represent risk attitudes of contract parties. We do not know any existing work capable of capturing any of the above legal doctrines.

Much work has been done to study formal argumentation for many aspects of law (Gordon 1994; Prakken and Sartor 1996; Bench-Capon and Sartor 2003; García and Simari 2004; Atkinson and Bench-Capon 2005; Bench Capon, Atkinson, and Chorley 2005; Prakken 2006; Gordon, Prakken and Walton 2007; Gaertner and Toni 2008; Dung and Thang 2009; Rahwan and Simari 2009). A special focus has been on reasoning with cases, whose main task is to construct a legal theory from past cases that produces the desired legal outcome and to persuade the judge on its validity (McCarty 1995; Bench-Capon and Sartor 2003). Berman and Hafner (1993) argued that disputants build arguments for or against such a legal theory from factors of the case but justify them by appealing to the value their acceptance would advance. Prakken (2002) illustrated a method for expressing such values in the system of Prakken and Sartor (1998). Sartor (2002) modelled reasoning with cases as dialectical theory construction via a set of operators directed by teleology. Abstract argumentation (Dung 1995) has been extended for case-based reasoning 
in Bench-Capon and Sartor (2003), Atkinson and Bench-Capon (2005), Bench-Capon et al. (2005), and Bench-Capon and Modgil (2009). There, a judge, seen as a theory constructor, decides on competitive theories, taking into account the preference over the social values they advance. Attention has been made to analyse how a judge considers a case factor as relevant (Roth and Verheij 2004) via argumentation. Systems capable of reasoning with cases include among others TAXMAN (McCarty 1995), HYPO (Ashley 1991; Bruninghaus 2003) and CABERET (Rissland and Skalak 1991). If one views contract dispute resolution as an instance of reasoning with cases, legal doctrines can be considered as guidelines and principles to make the interpretation of contracts less dependent on a judge's own preference and personality. Since legal doctrines have often been thoroughly examined, the social values they bring about are convincing and accountable. For instance, as repeatedly described in many legal sources (e.g. Freitel 2004; Lewison 2004), the doctrines for performance relief help in restoring the business efficacy of contracts. Thus, to articulate the values desired by the society, a judge is expected to argue 'deductively' with existing doctrines, but can argue 'inductively' with precedents to make new doctrines. Modelling a judge doing the latter task is beyond the scope of this paper.

Although abstract argumentation provides a natural platform for understanding many legal procedures, it does not provide a programming environment in which the arguments for such procedures could be constructed automatically. To address this issue, an instance of abstract argumentation called assumption-based argumentation (ABA), where the arguments are deductive proofs based on assumptions (Dung, Kowalski, and Toni 2006) could be used. Modular argumentation (Dung and Thang 2008, 2009) extends ABA to allow different modules of argumentation to be built separately and assembled together by different semantics. Thus one can mingle module references to achieve the effect of (possibly nested) modal operators of modal logics. However, in comparison with modal logics, modular argumentation has advantages, among others, of being directly executable and being easy to understand. For example, to represent professional knowledge that a party should have known, but may not have known at the time of contract making, modal logics would require a number of different modal operators with a doubtful necessity, making the semantics of the system difficult to understand. The presented formalism uses modular argumentation both as a programming and reasoning environment.

The contexts of contract consisting of different knowledge bases about beliefs and expertise of contract parties as well as about common social, legal domains at the time of contract making or performance need to be built. This is done during legal proceedings by exchanges of arguments between the parties and the judge. The acceptance of the exchanged arguments are based on permissible evidences, permissible common domain knowledge and social norms. While there is a significant body of research on protocols for such exchanges (Dung 1993; Gordon 1994; Prakken and Sartor 1996; Bench-Capon et al. 2005; Prakken 2006; Gordon et al. 2007), evidential reasoning in AI is less well studied (Bench-Capon and Prakken 2008). Poole (2001) has illustrated how a scenario-based approach can be modelled as adductive reasoning in his Theorist system. Bex et al. (2003) argues for the relevance of argumentation schemes, and the combination of argumentation schemes with scenario-based approach in (Bex et al. 2007). Argumentation schemes can be seen as semi-formal defeasible rules (Verheij 2003). An argumentation scheme is associated with a number of critical questions identifying attacks against arguments based on it. For example, an argumentation scheme for evidential reasoning 'If a witness says that $\mathrm{P}$ then P' has a critical question 'is the witness sincere?'. Argumentation schemes are rooted in informal argumentation (Walton 1996). Argumentation schemes can be represented in a nomonotonic logic like in (Verheij 2003), or ABA like in (Dung et al. 2009), or abstract argumentation framework like in (Atkinson and Bench-Capon 2008).

The paper is structured as follows. In Section 2, modular argumentation and contract representation are recalled. We model the legal doctrines of impossibility and frustration of 
purpose in Section 3. Section 4 applies modular argumentation to represent these legal doctrines. We conclude in Section 5.

\section{Backgrounds}

\subsection{Modular argumentation}

Argumentation is a form of reasoning that could be viewed as dispute resolution, in which the participants present their arguments to establish, defend or attack certain propositions. Probably, the most abstract among the well-known formalisms for argumentation is the abstract argumentation framework (Dung 1995) defined simply by a pair ( $\mathcal{A} \mathcal{R}$, att), where $\mathcal{A} \mathcal{R}$ is a set of arguments and att is a binary relation over $\mathcal{A} \mathcal{R}$ representing the relation that an $\operatorname{argument} A$ attacks an argument $B$ for $(A, B) \in$ att. The semantics of abstract argumentation is determined by the acceptability of arguments and various associated notions of extensions. For the purpose of this study, we introduce only one of them. A set of arguments $S$ attacks an argument $A$ if some argument in $S$ attacks $A ; S$ attacks another set $S^{\prime}$ if $S$ attacks some argument in $S^{\prime} ; S$ is conflict-free if it does not attack itself. $S$ is admissible if $S$ is conflict-free and it counter-attacks each attack against it. A maximal (w.r.t set inclusion) admissible set of arguments is called a preferred extension.

Although abstract argumentation provides a natural platform for understanding many legal procedures (Gordon 1994; Prakken and Sartor 1996; Bench-Capon and Sartor 2003; Atkinson and Bench-Capon 2005; Bench-Capon et al. 2005; Prakken 2006; Gordon et al. 2007), it does not provide a programming environment in which the arguments for such procedures could be constructed automatically. To address this issue, an instance of abstract argumentation called ABA where the arguments are deductive proofs based on assumptions (Dung et al. 2006) could be used. An ABA framework is a triple $(\mathcal{R}, \mathcal{A},-)$, where $\mathcal{R}$ is set of inference rules of the form $l_{0} \leftarrow l_{1}, \ldots l_{\mathrm{n}}$ (for $n \geq 0$ ), $\mathcal{A} \subseteq \mathcal{L}$ is a set of assumptions, and ${ }^{-}$is a (total) mapping from $\mathcal{A}$ into $\mathcal{L}$, where $\bar{x}$ is referred to as the contrary of $x$. Assumptions in $\mathcal{A}$ do not appear in the heads of rules in $\mathcal{R}$. A (backward) deduction of a conclusion $\alpha$ based on (or supported by) a set of premises $P$ is a sequence of sets $S_{1}, \ldots, S_{m}$, where $S_{i} \subseteq \mathcal{L}, S_{1}=\{\alpha\}, S_{m}=P$, and for every $i$, where $\sigma$ is the selected sentence in $S_{i}$ : If $\sigma$ is not in $P$ then $S_{i+1}=S_{i}-\{\sigma\} \cup S$ for some inference rule of the form $\sigma \leftarrow S \in \mathcal{R}$. Otherwise $S_{i+1}=S_{i}$.

For a set of propositions $X$, and some sentence $l$, we write $X \vDash l$ if there exists a backward deduction for $l$ based on some $X^{\prime} \subseteq X$. An argument for $x \in \mathcal{L}$ supported by a set of assumptions $X$ is a (backward) deduction of $x$ based on $X$ and denoted by $(x, X)$. An argument $(x, X)$ attacks an argument $(y, Y)$ if $x$ is the contrary of some assumption in $Y$. The abstract argumentation framework constructed from arguments of an ABA framework $\mathcal{F}$ is denoted by $\mathrm{AA}_{\mathcal{F}}$.

A direct semantics of $\mathcal{F}$ corresponding to that of $\mathrm{AA}_{\mathcal{F}}$ is as follows (Dung, Mancarella, and Toni 2007). A set of assumptions $S$ attacks an assumption $\alpha$ if there is an argument $(y, Y)$ with $Y \subseteq S$ and $y=\bar{\alpha}$. $S$ attacks another set of assumptions $S^{\prime}$ if $S$ attacks an assumption in $S^{\prime}, S$ is conflict-free if it does not attack itself. $S$ is admissible if $S$ is conflict-free and $S$ attacks each set of assumptions that attacks $S$. A maximal admissible set of assumptions is called a preferred set of assumptions.

A proposition $\pi \in \mathcal{L}$ is said to be a credulous consequence of $\mathcal{F}$, denoted by $\mathcal{F} \vdash_{\mathrm{cr}} \pi$ if it is supported by some preferred set of assumptions of $\mathcal{F}$, or equivalently it is supported by an argument in somepreferred extension of $A A_{\mathcal{F}} ; \pi$ is said to be a sceptical consequence of $\mathcal{F}$, denoted by $\mathcal{F} \vdash_{f \|} \pi$ if it is supported by each preferred set of assumptions of $\mathcal{F}$, or equivalently by some argument in each preferred extension of $A A_{\mathcal{F}}$.

Modular assumption-based argumentation (MABA) (Dung and Thang 2008) extending ABA is designed for larger-scale applications. The relationship between them is similar to the 
relationship between high-level programming languages and assembly languages. An MABA framework is structured into distinct modules where exactly one of them is considered as the main module while the others are called submodules. A module is basically an ABA framework with the exceptions that the premises in its rules are either sentences in $\mathcal{L}$ or a module call of the form call $(l, M, t)$, where $l$ is a non-assumption sentence in $\mathcal{L}, M$ is a module in which $l$ occurs and $t$ is the type of semantics of $M$ according to which $l$ is defined (i.e. $M \vdash{ }_{t} l$ ). Note that in this paper, we restrict ourselves to two types of semantics, notably the credulous $(t=\mathrm{cr})$ and sceptical preferred semantics $(t=\mathrm{sk})$ recalled shortly before; and to stratified MABA frameworks where the module names are ranked (by ordinals) such that all module calls in rules belonging to a module of rank $k$ refer to modules of ranks lower than $k$, like the MABA in Example 2.1.

Example 2.1 Let $\mathcal{F}$ be an MABA framework consisting of two modules $M_{1}, M_{0}$ where

$M_{0}$ consists of two rules $p \leftarrow \neg q$ and $q \leftarrow \neg p$ and $\mathcal{A}=\{\neg p, \neg q\}$ and $\overline{\neg p}=p$ and $\overline{\neg q}=q$.

$M_{0}$ has two preferred extensions $\{\neg p\}$ and $\{\neg q\}$.

Hence, $M_{0} \vdash_{\text {cr }} p$ and $M_{0} \vdash_{\text {cr }} q$ and both module calls - call ( $p, M_{0}$, cr) and call ( $q, M_{0}$, cr) - are accepted.

$M_{1}$ consists of a single rule:

$h \leftarrow \operatorname{call}\left(p, M_{0}, \mathrm{cr}\right)$, call $\left(q, M_{0}, \mathrm{cr}\right)$

As a result, $M_{1}$ has a unique extension in which $h$ is concluded.

Note that $\mathcal{F}$ is distinct to the ABA framework consisting of three rules: $h \leftarrow p, q$ and $p \leftarrow$ $\neg q$ and $q \leftarrow \neg p$, in which $h$ is not concluded wrt any semantics.

A (backward) deduction of a conclusion $\alpha$ w.r.t. module $M$ in MABA based on (or supported by) a set of premises $P$ is defined similarly as the backward deduction w.r.t ABA framework with the exception that when the selected element $\sigma$ is a module call of the form call $(l$, $N, t)$ then $N \vdash_{t} l$ and $S_{i+1}=S_{i}-\{\sigma\}$. The notions of arguments, extensions and consequences w.r.t a module $M$ are defined similarly as in usual ABA frameworks. For an MABA framework $\mathcal{F}$, we write $\mathcal{F} \vdash_{t} p$ if $M \vdash_{t} p$ where $M$ is the main module of $\mathcal{F}$ and $t \in\{\mathrm{cr}, \mathrm{sk}\}$. For $X \subseteq L$, by $\mathcal{F} \cup X$, we mean the framework obtained from $\mathcal{F}$ by adding $\{x \leftarrow \mid x \in X\}$ to its set of inference rules.

Modular argumentation provides an appropriate reasoning and programming environment for dispute resolution.

Example 2.2 (continue Example 1) By modelling the general common domain knowledge base and the belief base of the defendant at contract making as $\mathrm{ABAs} \mathrm{CK}_{\mathrm{d}}$ and $\mathrm{BO}$, respectively, the following arguments could be constructed automatically:

- The defendant (Caldwell) did not believe that fire may occur: BO $\nvdash_{\mathrm{cr}}$ Fire,

- Fire destroyed the hall: $\mathrm{CK}_{\mathrm{d}} \cup\{$ Fire $\} \vdash_{\text {sk }} \neg$ HallExist,

- The non-existence of the hall renders the rent of hall impossible: $\mathrm{CK}_{\mathrm{d}} \cup\{\neg$ HallExist $\} \vdash_{\text {sk }} \neg$ RentHall.

Thus a main module with $\mathrm{CK}_{\mathrm{d}}$, $\mathrm{BO}$ as submodules can construct an argument stating that the fire, an unexpected event for the defendant, destroyed the hall, the non-existence of which renders the rent of hall impossible.

\subsection{Contract}

There is huge research on formal representation of contracts (Farrell, Sergot, Sallé, and Bartolini 2005; Governatori and Milosevic 2006). However, for our purpose of ascertaining the mutual 
intention of contract parties as to the allocation of the risks of events occurring after contract making, the following extension of the representation in Dung and Thang (2008) suffices.

DeFINITION 2.3 A contract between contractor (also seller or provider) CO and contractee (also buyer or consumer) $C E$ is modelled as a five-tuple $T=\langle C O, C E, \tau, T, R A\rangle$, where

(1) $\tau$ identifies the transaction or services that contractor promises to perform,

(2) $T$ is a contract specification written in some contract language.

(3) RA allocates risks among the contract parties and consists of rules of the form $\varepsilon \rightarrow \mathrm{CX}$ stating that if event $\varepsilon$ occurs after the contract making, then the risk is allocated to $\mathrm{CX} \in$ $\{\mathrm{CO}, \mathrm{CE}\}$.

In cases where the identities of contract parties are clear from the context, we denote a contract by $\langle\tau, T, \mathrm{RA}\rangle$ or simply by $\langle\tau, T\rangle$ if RA is empty. Presenting a theory of contract languages is beyond the scope of this paper. For our purpose, we assume that there is a consequence relation $T \vDash \alpha$ stating that $\alpha$ can be derived from $T$.

Example 2.4 (continue Example 1.1) The contract is represented by <Caldwell, Taylor, RentHall, T, $\varnothing\rangle$ stating that Taylor contracts Caldwell to rent a hall. No risk allocation is given. $T$ specifies the contract price, $T=\{\operatorname{Price}(\pi)\}$ stating that the price of rent the hall is $\pi$.

\section{An argument-based formalism for contract dispute resolution}

Contracts are often specified only partially. A contract dispute arises when contract parties have conflicting views about the meaning of their contract, or its effect on their legal rights and obligations. The resolution of a contract dispute is governed by how the contract should be interpreted, thus in an abstract sense could be viewed as argumentation about contract interpretation whereby contract parties present arguments for or against a particular interpretation they wish to advance or reject, respectively.

A cornerstone principle for the court to resolve a contract dispute is to enforce a contract interpretation, called the hypothetical or complete intended contract, that reasonably represents the mutual intention of contract parties at the time they signed the contract. The court assumes that both parties are rational in order to equate their mutual intention with the intention of rational persons in the position with all their background (or contextual) knowledge. ${ }^{2}$ Because an actual contract is often viewed as representing the clearest mutual intention of contract parties, a hypothetical contract does not rewrite explicit contractual terms, instead adds implied terms representing the shared, but unexpressed intention of contract parties. To ascertain this kind of mutual intention objectively, the court generally applies well-established legal principles, guidelines and rules. Thus a dispute resolution can be modelled by a two-level modular argumentation process: at the object level, factors of the case are established from argumentation modules representing the contract context, while at the meta-level, argumentation modules representing legal principles and rules combine these factors to complete the actual contract with implied terms.

We establish the appropriateness of the above formalism by applying it to common law as that is the kind of law most studied in the literature. Common law has a case-by-case basis. As the vast and increasing number of cases lead to many conflicting decisions and an increased uncertainty in the law, Restatements (First and Second) of Contracts have been proposed to 'restate' clearly and precisely the principles and rules of common law (Steven and Melvin 2007) to make the interpretation of cases much easier and less arbitrary. Legal doctrines could be viewed as a widely accepted interpretation of the principles, guidelines and rules for 
dispute resolution. They present the way common law generally proceeds by distilling from a particular case the legal principle on which it is decided, and that legal principle is then generally applied to similar dispute contexts (Samuel 2000). In the remainder of this section, we will capture several legal doctrines in Restatement Second within the above formalism.

The doctrine that a failure to perform a considered promise constitutes a breach of contract insists on the literal performance of contracts in spite of the fact that events happening after contract signing make the contract onerous for one party. This doctrine is based on a legal principle that one of the main purposes of the contract as a legal and commercial institution is to allocate the risks of such events (Freitel 2004). However, this principle is not absolute in that contract parties could have a mutual, but unexpressed intention that a basic assumption for the formation of the contract is the non-occurrence of such events; so the occurrence of such events puts an end to the contract. Doctrines for performance relief allow the court to ascertain this unexpressed intention, and thus can be seen as providing a class of exceptions to the above doctrine of contract breach. The Restatement Second states:

'Where, after a contract is made, a party's performance is made impossible or a party's principal purpose is substantially frustrated without his fault by the occurrence of an event the non-occurrence of which is a basic assumption on which the contract was made, his duty to render that performance is discharged, unless the language or the circumstances indicate the contrary'.

DEFINITION 3.1 The support for rescission on the grounds of impossibility or frustration of purpose consists of the following conditions:

(1) that an unexpected event occurred after contract making,

(2) that the non-occurrence of the event was a basic assumption on which the contract was made,

(3) that the event is not the fault of the party asking for rescission,

(4) that the party asking for rescission does not bear the risk of that occurrence of the event either under the language of the contract or the surrounding circumstances.

\subsection{The doctrine of impossibility}

Following Definition 3.1, Caldwell's rescission in Taylor case is granted because (1) the fire is unexpected and occurred after the contract making; (2) the non-occurrence of fire is a basic assumption since fire destroyed the hall, an essential mean without which the contract is impossible to perform; (3) the fire is not caused by Caldwell and (4) no explicit clauses of the contract assigns risk of fire to Caldwell.

In (1) by not allowing Caldwell to rescind if the fire is expected, the doctrine takes a position that both parties actually intended to bear the risk of the fire. So the omission of explicit clauses expressing this actual intention in the contract merely means that contract parties did not trouble to write them down. Note that Caldwell is still not allowed to rescind if the fire is unexpected for him but expected for Taylor. This is because if a party could expect fire, then it may not be impossible for the other party to expect it as well. So the unexpectedness of the event for one party constitutes a mistake of this party. In general, a mistake by one party does not allow that party to repudiate its signed contract since the opposite would encourage the ignorance of necessary knowledge of the contract domain.

In (2) the destroyed means must be specifically referred to in the contract, or at least understood by both parties to be the property that would be used. Thus the court decision would be different if Caldwell has several halls and Taylor contracts to rent ' $a$ ' hall for performance without referring to any specific hall because it is still possible for Caldwell to give a hall for the concerts. 
In (4) the court may infer from 'the circumstances' implied risk allocation clauses. For the purpose of providing an efficient way to allocate the combined loss, many modern courts and law schools advocate that risk is allocated to a party who is able to foresee it but did not guard against it. The position taken here is that these are clauses the parties would have agreed on had they bargained with the unexpected event brought to their attention (assuming that they are rational persons). ${ }^{3}$ Thus, if Taylor case happened in our time, the ruling could be in favour of Taylor for the reason that the risk of fire should be allocated to Caldwell because fire not only is reasonably foreseeable but also can be prevented at a reasonable cost by installing sprinkler and alarm systems.

Forseeability needs to be differentiated from expectability. Condition 1 states that the event must be unexpected, but it does not mean that the event is unforeseeable. This is because 'a requirement of absolute non-foreseeability would be so logically inconsistent that in effect it would nullify the doctrine'. The following case illustrates the importance of this differentiation.

Example 3.2 (Opera Company v Wolf Trap foundation, 1987 (Farnsworth et al. 2001; Freitel 2004)) By agreement with Wolf Trap foundation, the Opera Company was to stage four summertime operatic performances at the Wolf Trap's concert center. Wolf Trap for its part agreed to pay $\$ 272,000$ and also to furnish the place of performance including an undertaking to provide lighting equipment as shall be specified by Opera Company. The final performance was cancelled when a severe thunderstorm caused an electrical outage and left the stage dark. Wolf Trap declined to pay the price of that performance and is sued by Opera Company. Wolf Trap defended on the ground that it is discharged under the doctrine of impossibility.

'We have experienced power outages on several occasions', according to an agent of Wolf Trap. The trial court said, in granting judgement against Wolf Trap, that if it could have foreseen the event, it was 'absolutely barred' from relying on the doctrine.

Wolf Trap appealed. The reviewing court was divided. The majority disagreed with the trial court on the reason it gave to exclude the application of the doctrine. The reason is that even though thunderstorm events are foreseeable but the scale of the thunderstorm was very severe and, hardly ever happened in the area. Hence condition 1 still holds.

The reviewing court still affirmed the trial decision, however based on the evidence that it was possible for Wolf Trap to install a backup power system to secure the performance. That means Wolf Trap was not excused from his performance because condition 4 did not hold, not because of condition 1 .

How should the court rule in Example 1.2? Condition 1 holds when neither party was warned at the contract making that Landsat satellites could malfunction at any time. Whether the other conditions hold depends on many factors. If Landsat 7 is mentioned in the contract as the sole data source or if Landsat 7 is the only data source that could be used for the contracted service, then: condition 2 holds since it is impossible for the GIS company to render its contracted service at areas that are not imaged by Landsat 7; condition 3 holds since the GIS company obviously did not cause the failure of the Scan Line Corrector; condition 4 holds since the GIS company can do nothing to prevent this event or mitigate its consequences. On the other hand, if Landsat 7 is not mentioned in the contract as the sole data source while there are other sensors capable of providing similar images, then condition 3 still holds, but conditions 2 and 4 fail since the GIS company can always render its service satisfactorily by using images from other sensors.

An event was unexpected for a party means that this party did not believe at the contract making that the event was possible. The court certainly does not allow it to declare so. 
Instead, the court reconstructs what it believed when signing the contract in light of the surrounding circumstances, then determines whether it possibly believed that the event is possible. Formally, this process could be modelled by constructing an argumentation module representing the party's belief base at contract making, then checking the existence of a credulously accepted argument that the event will happen. In contrast, to demonstrate that a party could foresee an event, an argumentation module representing the professional or expertise of the party at the time of contract making needs to be constructed, by for example looking at his education, training and experience that may not considered known or available to the general public. In general, to reason with a legal doctrine, the context of a contract, which consists of a number of distinct argumentation modules specifying the beliefs and professional knowledge of contract parties at the time of contract making, as well as temporal common knowledge and general common knowledge in the contract domain, needs to be constructed.

\subsubsection{Contract contexts}

Under the doctrine of impossibility, contexts are defined as shown below.

Definition 3.3 A context under the doctrine of impossibility of a contract $\Gamma=\langle\tau, \mathrm{T}, \mathrm{RA}\rangle$ between contractor $\mathrm{CO}$ and contractee $\mathrm{CE}$ is defined as a eight-tuple $\left\langle\varepsilon, \mathrm{BO}, \mathrm{BE}, \mathrm{CK}_{\mathrm{t}}, \mathrm{CK}_{\mathrm{d}}\right.$, $\mathrm{KO}, \mathrm{KE}, \mathrm{Cost}\rangle$, where $\varepsilon$ represents an unexpected event, $\mathrm{BO}, \mathrm{BE}, \mathrm{CK}_{\mathrm{t}}, \mathrm{CK}_{\mathrm{d}}$, are $\mathrm{ABAs}$ and

(1) $\mathrm{BO}, \mathrm{BE}$ contain the evidences and facts about the relevant beliefs of contractor $\mathrm{CO}$ and contractee $\mathrm{CE}$, respectively, at the time of making the contract.

(2) $\mathrm{CK}_{\mathrm{t}}$ describes a body of temporal common knowledge established by the court whose purpose is to establish that event $\varepsilon$ happened after the contract making.

(3) $\mathrm{CK}_{\mathrm{d}}$ describes a body of general common domain knowledge held by people with a rational mind in similar situations whose purpose is to establish objectively:

(a) whether $\varepsilon$ destroys or makes some means for performing $\tau$ unavailable,

(b) whether the unavailability of such a means renders the performance of $\tau$ impossible.

(4) $\mathrm{KO}, \mathrm{KE}$ describe respectively the professional knowledge or expertise that contractor $\mathrm{CO}$ and contractee $\mathrm{CE}$ are expected to know at the time of making the contract.

(5) Cost is a function specifying the cost of possible actions the contract parties could carry out to prevent $\varepsilon$ from happening, or substantially mitigate its consequences.

In cases where neither parties could do anything to prevent $\varepsilon$ or mitigate its consequences, contexts are simply represented by $\left\langle\varepsilon, \mathrm{BO}, \mathrm{BE}, \mathrm{CK}_{\mathrm{t}}, \mathrm{CK}_{\mathrm{d}}, \mathrm{KO}, \mathrm{KE}\right\rangle$.

We assume a language $\mathcal{L}$ containing a special event $E$ denoting the event of contract signing and a binary relation $\epsilon_{0} \sqsubset \epsilon_{1}$ between events stating that $\epsilon_{0}$ happens before $\epsilon_{1}$. $\mathcal{L}$ also contains fluents and actions, and a finite set of integers and a partial order $p \succ q$ between the integers representing that $p$ is greater than $q$ by orders of magnitude.

Example 3.4 (continue Example 1) The context of Taylor case $\left\langle\right.$ Fire, $\mathrm{BO}, \mathrm{BE}, \mathrm{CK}_{\mathrm{t}}, \mathrm{CK}_{\mathrm{d}}, \mathrm{KO}$, $\mathrm{KE}\rangle$ is constructed as follows.

- $\mathrm{BO}=\mathrm{BE}=(\mathcal{R}, \mathcal{A},-)$ represents that both parties believed (by common sense): 
- that the hall exists when the time of concerts comes:

$$
\mathcal{A}=\{\text { HallExist }\}, \overline{\text { HallExist }}=\neg \text { HallExist }
$$

- that it is impossible to rent the hall without its existence:

$$
\mathcal{R}=\left\{r_{1}: \neg \text { RentHall } \leftarrow \neg \overline{\text { HallExist }}\right\}
$$

- The idea of fire did not come up at all for both parties while negotiating for the contract. Hence there are no rules or assumptions referring to fire.

- As a matter of fact, the fire occurred after contract making:

$$
\mathrm{CK}_{\mathrm{t}}=\left(\mathcal{R}_{\mathrm{t}}, \mathcal{A}_{\mathrm{t}},-\right) \text { with } \mathcal{A}_{\mathrm{t}}=\oslash \text { and } \mathcal{R}_{\mathrm{t}}=\{E \subseteq \text { Fire } \leftarrow\}
$$

- As a matter of fact, the fire destroyed the hall:

$$
\begin{gathered}
\mathrm{CK}_{\mathrm{d}}=\left(\mathcal{R}_{\mathrm{d}}, \mathcal{A}_{\mathrm{d}},-\right) \text { with } \mathcal{A}_{\mathrm{d}}=\{\text { HallExist }\} \text { and } \mathcal{R}_{\mathrm{d}}=\left\{r_{1}, r_{2}\right\} \text {, where } \\
r_{2}: \neg \text { HallExist } \leftarrow \text { Fire }
\end{gathered}
$$

- Both parties did not have any expertise in mitigating the consequences of the fire: $\mathrm{KO}=$ $\mathrm{KE}=\mathrm{CK}_{\mathrm{d}}$.

Example 3.5 (continue Example 3.2) Excluding provisions irrelevant to the resolution of this dispute, the contract is represented by $\langle$ Opera, $\{$ Lighting, Price $(272 K)\}, \emptyset\rangle$ stating that contractor (Opera Company) is to stage operatic performances, and contractee (Wolf Trap), in return, pays the contract price of $\$ 272 \mathrm{~K}$ and provides lighting for the performances. No risk allocation clauses are given.

The context $\left\langle\right.$ Storm, BO, BE, $\left.\mathrm{CK}_{\mathrm{t}}, \mathrm{CK}_{\mathrm{d}}, \mathrm{KO}, \mathrm{KE}, \mathrm{Cost}\right\rangle$ is constructed as follows.

- $\mathrm{BO}=\left(\mathcal{R}_{0}, \mathcal{A}_{0},-\right)$ ) represents that Opera Company believed (by common sense) that:

- Power would be available when the time of the opera comes.

$$
\mathcal{A}_{0}=\{\text { Power }\}, \overline{\text { Power }}=\text { Outage }
$$

- Lighting is provided by power:

$$
r_{1}: \text { Lighting } \leftarrow \text { Power } \in R_{0}
$$

- Lighting cannot be provided if power outage occurs while there is no backup supply:

$$
r_{2}: \neg \text { Lighting } \leftarrow \text { Outage, } \neg \text { Backup } \in R_{0}
$$

- The opera cannot be performed without lighting:

$$
r_{3}: \neg \text { Opera } \leftarrow \neg \text { Lighting } \in R_{0}
$$


- Because the scale of the storm was so severe and hardly ever happened in the area, there are no rules or assumptions referring to Storm.

- Wolf Trap was aware that it did not have a backup power at the concert centre:

$$
\mathrm{BE}=\left(\mathcal{R}_{1}, \mathcal{A}_{0},-,\right) \text { with } \mathcal{R}_{1}=\mathcal{R}_{0} \cup\left\{r_{4}\right\} \text { where } r_{4}: \neg \text { Backup } \leftarrow
$$

- As a matter of fact, the storm occurred after contract making:

$$
\mathrm{CK}_{\mathrm{t}}=\left(\mathcal{R}_{\mathrm{t}}, \mathcal{A}_{\mathrm{t}},-\right) \text { with } \mathcal{A}_{\mathrm{t}}=\emptyset \text { and } \mathcal{R}_{\mathrm{t}}=\{E \subseteq \text { Storm } \leftarrow\}
$$

- As a matter of fact, the storm caused the power outage and the cost of preparing a backup supply is reasonable w.r.t. the contract price:

$$
\begin{gathered}
\mathrm{CK}_{\mathrm{d}}=\left(\mathcal{R}_{\mathrm{d}}, \mathcal{A}_{\mathrm{d}},-\right) \text { with } \mathcal{A}_{\mathrm{d}}=\mathcal{A}_{0} \text { and } \mathcal{R}_{\mathrm{d}}=\mathcal{R}_{1} \cup\left\{r_{5}, r_{6}\right\}, \text { where } \\
r_{5}: \text { Outage } \leftarrow \text { Storm } \\
r_{6}: 272 \succ \operatorname{Cost}(\text { Backup }) \leftarrow
\end{gathered}
$$

- Opera Company did not have any expertise in mitigating the consequences of the storm:

$$
\mathrm{KO}=\mathrm{BO}
$$

- Being a lessor in this area, Wolf Trap should be able to foresee that severe storms could occur (though rarely) during summertime, moreover should know that it can always provide Lighting by installing a backup supply:

$\mathrm{KE}=\left(\mathcal{R}_{2}, \mathcal{A}_{1},-,\right)$ with $\mathcal{A}_{1}=\{$ Power, Storm $\}, \overline{\text { Storm }}=\neg$ Storm and $\mathcal{R}_{2}=\mathcal{R}_{1} \cup\left\{r_{6}, r_{7}\right\}$, where $r_{7}$ : Lighting $\leftarrow$ Backup

In the following, we define the notion of impossibility formalising conditions 1 and 2 of Definition 3.1 to model the argument for a party's rescission: 'after a contract is made, the party's performance is made impossible by the occurrence of an unexpected event the nonoccurrence of which is a basic assumption on which the contract was made.'

Definition 3.6 Let $\mathrm{CNT}=\left\langle\varepsilon, \mathrm{BO}, \mathrm{BE}, \mathrm{CK}_{\mathrm{t}}, \mathrm{CK}_{\mathrm{d}}, \mathrm{KO}, \mathrm{KE}, \mathrm{Cost}\right\rangle$ be a context of contract $\Gamma=\langle\tau, T, \mathrm{RA}\rangle$ between contractor $\mathrm{CO}$ and contractee $\mathrm{CE}$. We say that $\Gamma$ is impossible w.r.t. $\mathrm{CNT}$ if the following conditions are satisfied:

(1) $\varepsilon$ happened after contract making and is unexpected for both parties, i.e.:

(a) $\mathrm{CK}_{\mathrm{t}} \vdash_{\mathrm{sk}} E \subseteq \varepsilon$, and

(b) $\mathrm{BO} \nvdash_{\mathrm{cr}} \varepsilon$ and $\mathrm{BE} \nvdash_{\mathrm{cr}} \varepsilon^{5}$

(2) the non-occurrence of $\varepsilon$ is a basic impossibility assumption on which the contract was made, i.e.:

(a) $\varepsilon$ destroys some means $m$ for $\tau$ : $\mathrm{CK}_{\mathrm{d}} \cup\{\varepsilon\} \vdash_{\mathrm{sk}} \neg m$, and

(b) $\tau$ is impossible to be performed without $m: \mathrm{CK}_{\mathrm{d}} \cup T \cup\{\neg m\} \vdash_{\text {sk }} \neg \tau$.

Example 3.7 (continue Example 3.4) The contract is impossible w.r.t. the context since: 
- Fire happened after contract making as $\mathrm{CK}_{\mathrm{t}} \vdash_{\mathrm{sk}} E \subseteq$ Fire.

- The fire is unexpected for both parties as there are no arguments supporting Fire from both $\mathrm{BO}$ and BE.

- Fire destroys HallExist as $\mathrm{CK}_{\mathrm{d}} \cup\{$ Fire $\} \vdash_{\text {sk }} \neg$ HallExist.

- RentHall is impossible to be performed without HallExist as $\mathrm{CK}_{\mathrm{d}} \cup\{\neg$ HallExist $\}$ $\vdash_{\mathrm{sk}} \neg$ RentHall.

Example 3.8 (continue example 3.5) The contract is impossible w.r.t. the context since:

- Storm happened after contract making as $\mathrm{CK}_{\mathrm{t}} \vdash_{\mathrm{sk}} E \subseteq$ Storm.

- This Storm is unexpected for both parties as there are no arguments supporting Storm from both $\mathrm{BO}$ and $\mathrm{BE}$.

- Storm destroyed Lighting, as $\mathrm{CK}_{\mathrm{d}} \cup\{$ Storm $\} \vdash_{\text {sk }} \neg$ Lighting

- Opera cannot be performed without Lighting as $\mathrm{CK}_{\mathrm{d}} \cup\{\neg$ Lighting $\} \vdash_{\text {sk }} \neg$ Opera.

\subsubsection{Complete intended contracts}

To attack an argument for rescission on the ground of impossibility, the party preventing relief may argue: 'although the contract is impossible, the party seeking relief cannot rescind because he is allocated the risk of the event'. Risk allocation could be explicitly stated by contractual terms or implied by courts from the context. We define the notion of complete intended contract incorporating two principles widely accepted by modern courts to do so. The first principle allocates the risk to a party if he caused the event. The second principle is based on efficiency stating that risks should be allocated to the party who could foresee the event but did not guard against it (Posner 2007). These two principles correspond to conditions 3 and 4 of Definition 3.1.

Definition 3.9 Let $\Gamma=\langle\tau, T, R A\rangle$ be a contract between $C O$ and $C E$ that is impossible w.r.t. context $C N T=\left\langle\varepsilon, B O, B E, C K_{\mathrm{t}} C K_{\mathrm{d}}, K O, K E, C o s t\right\rangle$. The complete intended contract of $\Gamma$ in the context $C N T$ is contract $\langle\tau, T, R B\rangle$, where $R B$ is obtained from $R A$ by adding risk allocation clauses $\varepsilon \rightarrow C X$ in two cases:

(1) CX caused $\varepsilon: \mathrm{CK}_{\mathrm{d}} \cup \mathrm{CK}_{\mathrm{t}} \vdash_{\text {sk }} \mathrm{Cause}(\mathrm{CX}, \varepsilon)$.

(2) $\mathrm{CX}$ is an efficient risk bearer of $\varepsilon$, in that:

a. $\mathrm{CX}$ is expected to know that $\varepsilon$ could happen: $\mathrm{KX} \vdash_{\mathrm{cr}} \varepsilon$, and

(b) $\mathrm{CX}$ could carry out a reasonable action $\alpha$ to:

i. prevent $\varepsilon$ from happening: $\mathrm{KX} \cup\{\alpha\} \vdash_{\mathrm{cr}} \neg \varepsilon^{6}$, or

ii. substantially mitigate its consequences: $\mathrm{KX} \cup\{\varepsilon, \alpha\} \vdash_{\mathrm{cr}} m^{7}$,

where $m$ is the destroyed means (see Definition 3.7)

An action $\alpha$ is said to be reasonable if its cost is reasonable wrt the contract price, i.e. $\pi \succ \operatorname{Cost}(\alpha)$, where $T \models \operatorname{Price}(\pi)$.

If $\mathrm{KX} \nvdash_{\mathrm{cr}} \varepsilon$, i.e. $\varepsilon$ was not foreseeable by $\mathrm{CX}$, then $\mathrm{CX}$ can hardly be expected to have provided provisions for it, or performed any prevention or mitigation actions. However, foreseeability $\mathrm{KX} \vdash_{\mathrm{cr}} \varepsilon$ alone does not necessarily prove the allocation of risk of $\varepsilon$ to CX since $\varepsilon$ may be beyond its capability w.r.t. the value of the contract.

Example 3.10 (continue Example 3.4) One of the following reasons is enough to conclude that there are no efficient risk bearers:

- Neither party is expected to foresee that fires could happen $\mathrm{KO} \nvdash_{\mathrm{cr}}$ Fire and $\left.\mathrm{KE}\right|_{\mathrm{cr}}$ Fire. 
- Neither party could do anything to prevent the fire or mitigate its consequence.

Example 3.11 (continue Example 3.5) Wolf Trap is an efficient risk bearer of event Storm since:

- Wolf Trap is expected to know that Storm could happen as $\mathrm{KE} \vdash_{\mathrm{cr}} \mathrm{Storm}$,

- Wolf Trap can still provide Lighting for the performance even if Storm occurs by provisioning a backup supply because $\mathrm{KE} \cup\{$ Backup $\} \vdash_{\text {cr }}$ Lighting,

- Provisioning a backup supply is a reasonable action for Wolf Trap.

The semantics of a contract under the doctrine of impossibility could be stated as follows: Without occurrence of unexpected events, contract parties have to perform their parts as given by the contract specification. If an unexpected event occurred, making the contract impossible, then a party could rescind the contract provided that he is not allocated the risk of the event in the complete intended contract.

By not allowing any party to rescind if the event causing the dispute is expected, the semantics takes a position that it is an actual intention of contract parties to bear the risk of the event. By allocating the risk of unexpected events to efficient risk bearers, the semantics takes a position that those clauses express the presumed intention of parties because the parties would have agreed on them had they bargained with unexpected events brought to their attention. Thus the semantics is in fact a refinement of the general principle that the court would resolve a contract dispute by enforcing an hypothetical contract that reasonably represents the mutual intention of the parties.

\subsection{The doctrine of frustration of purpose}

We first recall a famous court case below (Farnsworth et al. 2001; Freitel 2004) to illustrate this doctrine.

Example 3.12 (Krell v Henry, 1903) Krell (the contractor) rented his apartment to Henry for a two-day period. Henry's purpose in making this contract is to view the coronation of King Edward VII. Henry agrees to pay a price far beyond the ordinary rental value of the apartment for this privilege. The coronation is cancelled because the King is taken ill. Henry does not use the premises, refuses to make the payment and is sued by Krell.

The support for Henry's rescission is based on: (1) 'King's sick' is unexpected and occurred after the contract making; (2) the non-occurrence of 'King's sick' is a basic assumption of the contract since 'King's sick' leads to the cancellation, destroying Henry's principal goal in entering into the contract; (3) 'King's sick' is not caused by Henry; and (4) no explicit clauses of the contract assign the risk of this event to him.

This doctrine and the impossibility doctrine only differ in condition 2 of Definition 3.1. Under this doctrine, the party seeking relief needs to show that the occurrence of the unexpected event destroyed his principal goal in entering into the contract. However, in order to avoid it becoming an escape route for a party who entered into a bad bargain, the courts have adopted a restrictive interpretation that the unexpected event falsifies a commonly believed condition of which contrary is not within the contemplation of both parties, leading to the destruction of the principal goal of the party seeking relief (Freitel 2004; McKendrick 2005). In the above case, such a commonly believed condition is that the 'coronation' would be held. Hence, if Henry was unable to watch the coronation because of his illness, then the contract should not have been discharged since his principal goal was destroyed but not by any commonly believed condition. 
The notion of contract contexts under this doctrine is defined as in Definition 3.3 except that a new component $g$ representing the principal goal in entering into the contract of the party seeking relief is added.

Definition 3.13 A context under the doctrine of frustration of purpose of a contract $\Gamma=$ $\langle\tau, T, R A\rangle$ between contractor $C O$ and contractee $C E$ is defined as a nine-tuple $\left\langle\varepsilon, g, B O, B E, C K_{\mathrm{t}} C K_{\mathrm{d}}, K O, K E, C o s t\right\rangle$, where $C K_{\mathrm{d}}$ represents the general common knowledge established by the court to determine whether event $\varepsilon$ leads to the destruction of goal g, and other components are defined as in Definition 3.3.

The notion of frustration covering conditions 1 and 2 (in Definition 3.1) is defined as below.

Definition 3.14 Let $C N T=\left\langle\varepsilon, g, B O, B E, C K_{\mathrm{t}} C K_{\mathrm{d}}, K O, K E\right.$, Cost $\rangle$, be a context of contract $\Gamma=\langle\tau, T, R A\rangle$ between contractor $C O$ and contractee $C E$. We say that $\Gamma$ is frustrated wrt CNT if

(1) $\varepsilon$ happened after contract making and is unexpected for both parties (as formalised in Definition 3.6), and

(2) the non-occurrence of $\varepsilon$ is a basic frustration assumption on which the contract was made in that the following conditions are satisfied:

(a) the occurrence of $\varepsilon$ falsifies a condition $\lambda$ that is commonly believed by both parties, i.e:

- both parties believed that $\lambda$ holds: $\mathrm{BO} \vdash_{\mathrm{sk}} \lambda$ and $\mathrm{BE} \vdash_{\mathrm{sk}} \lambda^{9}$, and

- the occurrence of $\varepsilon$ falsifies $\lambda$ : $\mathrm{CK}_{\mathrm{d}} \cup\{\varepsilon\} \vdash_{\mathrm{sk}} \neg \lambda$.

(b) both parties (fully) believed that if $\lambda$ is true then the performance of the contract fulfills goal $g$ : BO $\cup\{\tau, \lambda\} \vdash_{\text {sk }} g$ and $\mathrm{BE} \cup\{\tau, \lambda\} \vdash_{\text {sk }} g$.

(c) $g$ is totally destroyed when $\lambda$ is false: $\mathrm{CK}_{\mathrm{d}} \cup\{\tau, \neg \lambda\} \vdash_{\text {sk }} \neg g$.

Note that condition 2(c) is different to $\mathrm{CK}_{\mathrm{d}} \cup\{\tau, \neg \lambda\} \neg \vdash_{\mathrm{cr}} g$. While condition 2(c) requires that goal $g$ is totally destroyed or all parts of $g$ is destroyed, the latter condition only requires that goal $g$ in its entirety is not fulfilled. We will see this fine but very important point in Example 3.16 .

The notion of complete intended contract under this doctrine is defined as in Definition 3.9 except that condition 2(b)ii $\mathrm{KX} \cup\{\varepsilon, \alpha\} \vdash_{\text {cr }} \tau$ is replaced by $\mathrm{KX} \cup\{\varepsilon, \alpha, \tau\} \vdash_{\text {cr }} g$ stating that by doing $\alpha$, the goal $g$ can still be fulfilled.

Example 3.15 (continue Example 3.12) The contract is represented by $\langle\operatorname{RentRoom}, T$, $\emptyset\rangle$ for some $T$ not needed to be specified in our analysis. No risk allocation is given.

The context $\left\langle\right.$ KingSick, ViewCoronation, $\left.\mathrm{BO}, \mathrm{BE}, \mathrm{CK}_{\mathrm{t}}, \mathrm{CK}_{\mathrm{d}}, \mathrm{KO}, \mathrm{KE}\right\rangle$ is constructed as follows.

- $\mathrm{BO}=\mathrm{BE}=\left(\mathcal{R}_{0}, \mathcal{A}_{0},-\right)$ represents that both parties believed (by common sense):

- that the coronation is to be held:

$$
\mathcal{A}_{0}=\{\text { Coronation }\}, \overline{\text { Coronation }}=\text { Coronation }
$$

- that Henry can view the coronation if he rents the room and the coronation is held:

$$
r_{1} \text { : ViewCoronation } \leftarrow \text { RentRoom, Coronation } \in \mathcal{R}_{0}
$$


- that one cannot view the coronation if it is not held:

$$
r_{2}: \neg \text { ViewCoronation } \leftarrow \neg \text { Coronation } \in \mathcal{R}_{0}
$$

- The idea of King's sickness did not come up at all for both parties while negotiating for the contract. Hence, there are no rules or assumptions referring to KingSick.

- As a matter of fact, the King is sick after the contract signing:

$$
\mathrm{CK}_{\mathrm{t}}=\left(\mathcal{R}_{\mathrm{t}}, \mathcal{A}_{\mathrm{t}},-\right) \text { with } \mathcal{A}_{\mathrm{t}}=\emptyset \text { and } \mathcal{R}_{\mathrm{t}}=\{E \sqsubseteq \text { KingSick } \leftarrow\} \text {. }
$$

- As a matter of fact, the coronation is cancelled because of the King's sickness

$$
\begin{aligned}
& \mathrm{CK}_{\mathrm{d}}=\left(\mathcal{R}_{\mathrm{d}}, \mathcal{A},-\right) \text { with } \mathcal{R}_{\mathrm{d}}=\left\{r_{1}, r_{2}, r_{3}\right\} \text { where: } \\
& r_{3}: \neg \text { Coronation } \leftarrow \text { KingSick }
\end{aligned}
$$

- Both parties did not have any expertise or professional knowledge to prevent the sickness of the King or mitigate the consequences of this event:

$$
\mathrm{KO}=\mathrm{KE}=\mathrm{BO}=\mathrm{BE}
$$

The non-occurrence KingSick is a basic frustration assumption on which the contract was made since:

- KingSick falsifies the commonly believed condition that the coronation is held as:

$$
\begin{gathered}
\text { - } \mathrm{BO} \vdash_{\mathrm{sk}} \text { Coronation and } \mathrm{BE} \vdash_{\mathrm{sk}} \text { Coronation } \\
\mathrm{C} \mathrm{CK}_{\mathrm{d}} \cup\{\text { KingSick }\} \vdash_{\mathrm{sk}} \neg \text { Coronation }
\end{gathered}
$$

- Both parties believed that if the coronation is held, then the performance of the contract fulfills the goal ViewCoronation as:

$$
\begin{aligned}
& -\quad \mathrm{BO} \cup\{\text { RentRoom, Coronation }\} \vdash_{\text {sk }} \text { ViewCoronation } \\
& \text { - } \quad \mathrm{BE} \cup\{\text { RentRoom, Coronation }\} \vdash_{\text {sk }} \text { ViewCoronation }
\end{aligned}
$$

- The goal ViewCoronation is totally destroyed when the coronation is cancelled as:

$$
\mathrm{CK}_{\mathrm{d}} \cup\{\text { RentRoom, } \neg \text { Coronation }\} \vdash_{\text {sk }} \neg \text { ViewCoronation }
$$

Neither parties are allocated the risk of KingSick in the complete intended contract since both cannot do any thing to prevent KingSick or mitigate its consequences.

There are many cases which seemingly reject the argument of rescission by frustration. An interesting coronation case often contrasted with Krell v Henry is in the following. Our formal analysis of this case rather confirms the application of the doctrine of frustration of purpose.

Example 3.16 (Herne Bay Steamboat Co v Hutton, 1903 (Farnsworth et al. 2001)) Hutton (the contractee) hired a pleasure boat from Steamboat Company for the purpose of 'viewing the naval review of King Edward VII and a day's cruise round the fleet' on coronation day. 
Hutton apparently intended to sell seats on the boat to those who wished to see the naval review, and no doubt suffered loss in consequence of the cancellation of the naval review, even though the fleet remained. The court held that Hutton is not entitled to the defence of frustration because it regarded the contract as one for the hire of a boat for sightseeing and only one of the anticipated attractions (the review) had failed to materialise.

The contract is represented by $\langle$ HireBoat, $T, \emptyset\rangle$ for some contract specification $T$ irrelevant in the resolution of this dispute.

The context $\left\langle\right.$ KingSick, SightSeeing, $\left.\mathrm{BO}, \mathrm{BE}, \mathrm{CK}_{\mathrm{t}}, \mathrm{CK}_{\mathrm{d}}, \mathrm{KO}, \mathrm{KE}\right\rangle$ is constructed as follows:

- $\mathrm{BO}=\mathrm{BE}=\left(\mathcal{R}_{0}, \mathcal{A}_{0},-\right)$ represents that both parties believed:

- that (by common sense) the naval review is to be held, and the fleet is to remain:

$$
\begin{aligned}
\mathcal{A}_{0} & =\{\text { NavalReview, Fleet }\} \text { where } \overline{\text { NavalReview }}=\neg \text { NavalReview and } \overline{\text { Fleet }} \\
& =\neg \text { Fleet }
\end{aligned}
$$

- that the contractee (Hutton) hired the boat for sightseeing of both the naval review and the fleet:

$$
\mathcal{R}_{0}=\left\{r_{1}: \text { SightSeeing } \leftarrow \text { NavalReview, Fleet, HireBoat }\right\}
$$

- As a matter of fact, the King is sick after the contract signing:

$$
\mathrm{CK}_{\mathrm{t}}=\left(\mathcal{R}_{\mathrm{t}}, \mathcal{A}_{\mathrm{t}},-\right) \text { with } \mathcal{A}_{\mathrm{t}}=\emptyset \text { and } \mathcal{R}_{\mathrm{t}}=\{E \subseteq \text { KingSick } \leftarrow\}
$$

- As a matter of fact, the naval review is cancelled because of the King's sickness:

$$
\begin{aligned}
& \mathrm{CK}_{\mathrm{d}}=\left(\mathcal{R}_{\mathrm{d}}, \mathcal{A}_{0},-\right) \text { with } \mathcal{R}_{\mathrm{d}}=\left\{r_{1}, r_{2}, r_{3}\right\}, \text { where } \\
& r_{2}: \neg \text { NavalReview } \leftarrow \text { KingSick } \\
& r_{3}: \neg \text { SightSeeing } \leftarrow \neg \text { NavalReview, } \neg \text { Fleet, HireBoat }
\end{aligned}
$$

- $r_{3} \in \mathcal{R}_{\mathrm{d}}$ as the contract is regarded as one for the hire of a boat for sightseeing of attractions including both the naval review and the fleet.

- Both parties did not have any expertise or professional knowledge to prevent the sickness of the King or mitigate the consequences of this event:

$$
\mathrm{KO}=\mathrm{BO} \text { and } \mathrm{KE}=\mathrm{BE} .
$$

The non-occurrence of KingSick is not a basic frustration assumption on which the contract was made since the goal SightSeeing is not totally destroyed when the naval review is cancelled as

$$
\mathrm{CK}_{\mathrm{d}} \cup\{\text { HireBoat, } \neg \text { NavalReview }\} \neg \vdash_{\mathrm{sk}} \neg \text { SightSeeing }
$$

even though:

- KingSick falsifies a condition commonly believed by both parties that the naval review would be held: 
$\mathrm{BO} \vdash_{\mathrm{sk}}$ NavalReview and $\mathrm{BE} \vdash_{\mathrm{sk}}$ NavalReview

$$
\mathrm{CK}_{\mathrm{d}} \cup\{\text { KingSick }\} \vdash_{\text {sk }} \neg \text { NavalReview }
$$

- both parties believed that if the naval review is held, then the performance of the contract fulfils the goal SightSeeing:

$$
\begin{aligned}
& - \\
& \text { - } \\
& \text { BO } \cup\{\text { HireBoat, NavalReview }\} \vdash_{\text {sk }} \text { SightSeeing } \\
&
\end{aligned}
$$

Note that part of goal SightSeeing is still fulfilled but the goal in its entirety is not, i.e. $\mathrm{CK}_{\mathrm{d}} \cup\{$ HireBoat, KingSick $\} \neg \vdash_{\mathrm{cr}}$ SightSeeing.

The semantics of a contract under the doctrine of frustration of purpose could be stated as follows: Without the occurrence of unexpected events, both parties have to perform their parts as given by the contract specification. If an unexpected event occurred, making the contract frustrated, then the party whose principal goal is destroyed could rescind the contract provided that he is not allocated the risk of the event in the complete intended contract.

\section{Modelling legal doctrines by modular argumentation}

\subsection{The doctrine of impossibility}

Given a contract $\Gamma=\langle\tau, T$, RA $\rangle$ between $\mathrm{CO}$ and $\mathrm{CE}$ and a context $\mathrm{CNT}=$ $\left\langle\varepsilon, \mathrm{CK}_{\mathrm{t}}, \mathrm{CK}_{\mathrm{d}}, \mathrm{KO}, \mathrm{BO}, \mathrm{KE}, \mathrm{BE}, \mathrm{Cost}\right\rangle$ of $\Gamma$ under the impossibility doctrine, we present a modular ABA framework consisting of submodules representing the context together with a main module denoted by $T h_{\Gamma}$ for representing the doctrines for contract breach and impossibility.

Formally, $T h_{\Gamma}$ is a modular ABA framework consisting of rules and facts defined in the following where the assumptions in $T h_{\Gamma}$ are represented by negative literals whose contraries are the corresponding positive literals:

1 Self-explaining facts Contract $(\mathrm{CO}, \mathrm{CE}, \Gamma)$, Transaction $(\tau, \Gamma)$, Price $(\pi, \Gamma)$

2 A fact Happen $(\varepsilon, \Gamma)$ stating that event $\varepsilon$ happened after making the contract. Note that $\varepsilon$ is a constant in the language of $T h_{\Gamma}$.

3 A rule of the form

$$
\text { RiskAllocatedTo(CX, } \Gamma) \leftarrow \operatorname{Happen}(\epsilon, \Gamma)
$$

for each risk allocating rule $\epsilon \rightarrow \mathrm{CX}$ in RA

4 Two rules representing the doctrine that a failure to perform a considered promise constitutes a breach of contract. Formally these rules state that if $\mathrm{CX}$ is a party in a contract $\Gamma$ then CX must perform his part of the bargain in the contract unless there are exceptions for him to rescind it:

$$
\begin{gathered}
\operatorname{Pay}(\mathrm{CE}, \pi) \leftarrow \operatorname{Contract}(\mathrm{CO}, \mathrm{CE}, \Gamma), \operatorname{Transaction}(\tau, \Gamma), \operatorname{Price}(\pi, \Gamma)^{10} \\
\operatorname{Perform}(\mathrm{CO}, \tau), \neg \operatorname{Rescind}(\mathrm{CE}, \Gamma) \\
\operatorname{Perform}(\mathrm{CO}, \tau) \leftarrow \operatorname{Contract}(\mathrm{CO}, \mathrm{CE}, \Gamma), \operatorname{Transaction}(\tau, \Gamma), \neg \operatorname{Rescind}(\mathrm{CO}, \Gamma)
\end{gathered}
$$


5 The doctrine of impossibility provides a class of exceptions to the doctrine of contract breach to discharge a party from performing his promise when the contract is impossible due to an unexpected event he does not bear the risk of, and is represented by

$$
\text { Rescind }(\mathrm{CX}, \Gamma) \leftarrow \operatorname{Impossibility}(\Gamma), \neg \text { RiskAllocatedTo(CX, } \Gamma)
$$

6 The following rules capture the notion of impossibility according to Definition 3.6:

$$
\begin{aligned}
& \operatorname{Impossibility}(\Gamma) \leftarrow \operatorname{UnExpected}(\varepsilon), \operatorname{ViolateBA}(\Gamma) \\
& \operatorname{ViolateBA}(\Gamma) \leftarrow \operatorname{call}\left(\neg m, \mathrm{CK}_{\mathrm{d}} \cup\{\varepsilon\}, \operatorname{sk}\right), \operatorname{call}\left(\neg \tau, \mathrm{CK}_{\mathrm{d}} \cup T \cup\{\neg m\}, \text { sk }\right) \\
& \operatorname{UnExpected}(\varepsilon) \leftarrow \operatorname{Happen}(\varepsilon, \Gamma), \neg \operatorname{Expected}(\varepsilon) \\
& \operatorname{Expected}(\varepsilon) \leftarrow \operatorname{call}(\varepsilon, \mathrm{BE}, \mathrm{cr}) \\
& \operatorname{Expected}(\varepsilon) \leftarrow \operatorname{call}(\varepsilon, \mathrm{BO}, \mathrm{cr})
\end{aligned}
$$

7 The following rule allocates risks to parties causing unexpected situations according to part 1 of Definition 3.9:

$$
\text { RiskAllocatedTo }(C X, \Gamma) \leftarrow \operatorname{call}\left(\operatorname{Cause}(\mathrm{CX}, \varepsilon), \mathrm{CK}_{\mathrm{t}} \cup \mathrm{CK}_{\mathrm{d}}, \mathrm{sk}\right)^{11}
$$

8 The following allocates risks to sufficient risk bearers according to part 2 of Definition 3.9.

$$
\begin{aligned}
& \text { RiskAllocatedTo }(\mathrm{CX}, \Gamma) \leftarrow \operatorname{call}(\varepsilon, \mathrm{KX}, \mathrm{cr}), \operatorname{PrevOrMiti}(\mathrm{CX}, \varepsilon) \\
& \text { PrevOrMiti }(\mathrm{CX}, \varepsilon) \leftarrow \operatorname{ReasonableAction}(\mathrm{CX}, \alpha), \\
& \qquad \operatorname{call}(\tau, \mathrm{KX} \cup\{\varepsilon\} \cup\{\alpha\}, \operatorname{cr}) \\
& \text { PrevOrMiti }(\mathrm{CX}, \varepsilon) \leftarrow \operatorname{ReasonableAction}(\mathrm{CX}, \alpha), \operatorname{call}(\neg \varepsilon, \mathrm{KX} \cup\{\alpha\}, \operatorname{cr}) \\
& \text { ReasonableAction }(\mathrm{CX}, \alpha) \leftarrow \operatorname{Action}(\mathrm{CX}, \alpha), \operatorname{Price}(\pi, \Gamma), \pi \succ \operatorname{Cost}(\alpha)
\end{aligned}
$$

DeFINITION 4.1 Given a contract $\Gamma=\langle\tau, T$, RA $\rangle$ between $\mathrm{CO}$ and $\mathrm{CE}$ and a context $\mathrm{CNT}=$ $\left\langle\varepsilon, \mathrm{CK}_{\mathrm{t}}, \mathrm{CK}_{\mathrm{d}}, \mathrm{KO}, \mathrm{BO}, \mathrm{KE}, \mathrm{BE}, \mathrm{Cost}\right\rangle$ of $\Gamma$ under the impossibility doctrine. The legal theory of $\Gamma$ with respect to the impossibility doctrine in $\mathrm{CNT}$, denoted by $\mathcal{F}_{\Gamma, \mathrm{CNT}}$, is the MABA framework consisting of $T h_{\Gamma}$ as the main module and the $\mathrm{ABA}$ frameworks $\mathrm{CK}_{\mathrm{t}}, \mathrm{CK}_{\mathrm{d}}, \mathrm{KO}$, $\mathrm{BO}, \mathrm{KE}, \mathrm{BE}$ as submodules.

Positive literals of the form $\operatorname{call}(\alpha, M, t)$ in $T h_{\Gamma}$ are called input literals of $T h_{\Gamma}$. A set of input literals is consistent if it contains no two literals of the form $\operatorname{call}(\alpha, M, \operatorname{sk})$ and $\operatorname{call}(\neg \alpha, M, t)$. It is not difficult to see.

Theorem 4.2 Let $\Gamma=\langle\tau, T, R A\rangle$ be a contract between $C O$ and $C E$ and $C N T=$ $\left\langle\varepsilon, C K_{\mathrm{t}}, C K_{\mathrm{d}}, K O, B O, K E, B E\right.$, Cost $\rangle$ be a context of $\Gamma$ under the doctrine of impossibility. The following assertions hold:

$1 T h_{\Gamma} \cup S$ has an unique preferred extension ${ }^{12}$ where $S$ is a consistent set of input literals of $T h_{\Gamma}$.

2 If $\mathcal{F}_{\Gamma, \mathrm{CNT}} \vdash_{\mathrm{sk}}$ Rescind $(\mathrm{CX}, \Gamma)$ then the contract $\Gamma$ is impossible w.r.t the context $\mathrm{CNT}$ and the risk is not allocated to $\mathrm{CX}$ under the doctrine of impossibility and hence CX could rescind the contract. 
Proof $T h_{\Gamma} \cup S$ is stratified in the sense that the predicates in it could be ranked with decreasing order as follows:

\{Pay $\},\{$ Perform $\},\{$ Rescind $\},\{$ Impossibility, RiskAllocatedTo $\}$,

\{UnExpected, ViolateBA, PrevOrMiti\}, \{Expected, Happen, ReasonableAction\},

\{Action, Price, Cost, Contract, Transaction, call\}.

In (Bondarenko, Dung, Kowalski, and Toni 1997; Dung et al. 2006), it has been shown that stratified ABA frameworks have exactly one preferred extension that is also grounded and stable. It could be shown in almost exact the same way that $T h_{\Gamma} \cup S$ has an unique preferred extension that is also grounded, and stable.

The second statement follows immediately from the structures of the rules.

\subsection{The doctrine of frustration of purpose}

Let $\Gamma=\langle\tau, T, \mathrm{RA}\rangle$ be a contract between $\mathrm{CO}$ and $\mathrm{CE}$ and $\mathrm{CNT}$ be a context of CNT = $\left\langle\varepsilon, g, \mathrm{CK}_{\mathrm{t}}, \mathrm{CK}_{\mathrm{d}}, \mathrm{KO}, \mathrm{BO}, \mathrm{KE}, \mathrm{BE}, \mathrm{Cost}\right\rangle$ under the doctrine of frustration of purpose. The legal theory of $\Gamma$ with respect to the doctrine of frustration of purpose is defined analogously to the legal theory with respect to the doctrine of impossibility (Definition 4.1), except that the rules, in parts 5, 6 and the second rule in part 8 of the main module $T h_{\Gamma}$ are substituted by the following rules, with CX being the party whose principal goal $g$ is destroyed.

$$
\begin{aligned}
& \text { Rescind }(\mathrm{CX}, \Gamma) \leftarrow \text { Frustration }(\mathrm{CX}, \Gamma), \neg \text { RiskAllocatedTo }(\mathrm{CX}, \Gamma) \\
& \text { Frustration }(\mathrm{CX}, \Gamma) \leftarrow \operatorname{UnExpected}(\varepsilon) \text {, ViolateBA }(\mathrm{CX}, \Gamma) \\
& \text { ViolateBA }(\mathrm{CX}, \Gamma) \leftarrow \mathrm{CommonBelief}(\lambda, \operatorname{call}(g, \mathrm{BO} \cup\{\tau, \lambda\}, \mathrm{sk}) \\
& \operatorname{call}(g, \mathrm{BE} \cup\{\tau, \lambda\}, \mathrm{sk}), \operatorname{call}\left(\neg g, \mathrm{CK}_{\mathrm{d}} \cup\{\tau, \neg \lambda\}\right. \text {, sk) } \\
& \operatorname{CommonBelief}(\lambda) \leftarrow \operatorname{call}(\lambda, \mathrm{BO}, \operatorname{cr}), \operatorname{call}(\lambda, \mathrm{BE}, \mathrm{cr}), \operatorname{call}\left(\neg \lambda, \mathrm{CK}_{\mathrm{d}} \cup\{\varepsilon\}, \mathrm{sk}\right) \\
& \text { PrevOrMiti }(\mathrm{CX}, \varepsilon) \leftarrow \text { ReasonableAction }(\mathrm{CX}, \alpha), \operatorname{call}(g, \mathrm{KX} \cup\{\varepsilon, \alpha, \tau\}, \mathrm{cr})
\end{aligned}
$$

Thus the following theorem is analogous to Theorem 4.2.

Theorem 4.3 Let $\Gamma=\langle\tau, T, R A\rangle$ be a contract between $C O$ and $C E$ and $C N T=$ $\left\langle\varepsilon, g, C K_{\mathrm{t}}, C K_{\mathrm{d}}, K O, B O, K E, B E\right.$, Cost $\rangle$ be a context of $\Gamma$ under the doctrine of frustration of purpose. The following assertions hold:

(1) $T h_{\Gamma} \cup S$ has a unique preferred extension, where $S$ is a consistent set of input literals of $T h_{\Gamma}$.

(2) If $\mathcal{F}_{\Gamma, \mathrm{CNT}} \vdash_{\mathrm{sk}}$ Rescind $(\mathrm{CX}, \Gamma)$ then the contract $\Gamma$ is frustrated w.r.t the context $\mathrm{CNT}$ and the risk is not allocated to $\mathrm{CX}$ under the doctrine of frustration of purpose and hence $\mathrm{CX}$ could rescind the contract. 


\section{Conclusions and future work}

In this paper, we presented an argument-based formalism of contract dispute resolution following a modern view that the court would resolve a contract dispute by enforcing an interpretation of contract that reasonably represents the mutual intention of contract parties. We established the appropriateness of the formalism by applying it to resolve disputes over performance relief with the doctrines of impossibility and frustration of purpose. The formalism is represented by modular argumentation frameworks (Dung and Thang 2008, 2009), a reasoning and programming environment for dispute resolution based on ABA. Our experimented system called MOdular Argumentation for DIspute ReSOlution (MoDiSo) consists of two doctrines modelled in this paper and the doctrine of mutual mistake modelled in our related paper (Dung and Thang 2008, 2009).

In practice, the construction of context is done during legal proceedings by exchanges of arguments between the parties and the judge. The acceptance of the exchanged arguments are based on permissible evidences, permissible common domain knowledge and social norms. Protocols for such exchanges could be inspired by a huge body of research on this topic in the literature (Dung 1993; Gordon 1994; Prakken and Sartor 1996; Bench-Capon et al. 2005; Prakken 2006; Goron et al. 2007). We believe that for practical system of dispute resolution, procedures for contract dispute resolution along these lines play an essential role.

\section{Acknowledgements}

This work was partially funded by the Sixth Framework IST programme of the European Commission under the 035200 ARGUGRID project.

\section{Notes}

1. The Scan Line Corrector of Landsat 7 failed on 31 May 2003 (http://landsat.usgs.gov).

2. This view is recently restarted by Lord Hoffmann in Investors Compensation Scheme Ltd v West Bromwich Building Society, 1998 as principles of the interpretation of contracts probably known by heart by many commercial layers (Lewison 2004; McMeel 2007): 'Interpretation is the ascertainment of the meaning which the document would convey to a reasonable person having all the background knowledge which would be reasonably have been available to the parties in the situation in which they were at the time of the contract.... The background ... includes absolutely anything which would have affected the way in which the language of the document would have been understood by a reasonable man'.

3. In legal literatures (Lewison 2004), this kind of mutual intention is often referred to as presumed intention to differ it from the actual intention ascertained in condition 1.

4. Said Judge Clark in L.N Jackson \& Co v Royal Norwegian Government, 1949. . . 'Certainly the death of a promiser, the burning of a ship, the requisitioning of a merchant marine on the outbreak of a war could, and perhaps should, be foreseen'. This view is later echoed by many other judges.

5. Relation $\mathrm{BX} / f_{\mathrm{cr}} \varepsilon$ says that there is no credulously accepted arguments for $\varepsilon$ in $\mathrm{BX}$. Thus rationally CX should not believe that $\varepsilon$ could happen. Since the event does not necessarily to be unforeseeable, it is not the case that $\mathrm{KX}{ }_{\mathrm{cr}} \varepsilon$.

6. Similar to the risk allocation principle based on efficiency in (Dung and Thang 2009), $\mathrm{KX} \cup\{\alpha\} \vdash_{\mathrm{sk}} \neg \varepsilon$ or $\mathrm{KX} \cup\{\varepsilon, \alpha\} \vdash_{\text {sk }} m$ would be rather strong conditions as practically one may take precaution to prevent fire or mitigate its consequences but fire could still happen and burn down one's hall.

7. One may ask why not include condition $\mathrm{KX} \cup T \cup\{\varepsilon, \alpha\} \vdash_{\mathrm{cr}} \tau$ representing that action $\alpha$ could save some means other than the destroyed one so that transaction $\tau$ could still be performed. This is not necessary because this condition would exclude the application of the doctrine already as condition 2(b) of Definition 3.6 fails, like in the twisted Taylor case discussed at the beginning of this section, where the defendant Caldwell has several halls.

8. In (Dung et al. 2009) we did not model this restrictive interpretation. 
9. One may ask why not require $\mathrm{BX} \vdash_{\mathrm{cr}} \lambda$. If $\mathrm{BX} \vdash_{\mathrm{cr}} \lambda$ but $\mathrm{BX} \vdash_{\mathrm{sk}} \lambda$, then it cannot be said that $\neg \lambda$ is not within the contemplation of the parties at the time of entry into the contract. For example, if Krell $\mathrm{v}$ Henry happened in the makeup coronation, then the contract should not be discharged as both parties should know that the coronation might be cancelled again.

10. Note that we make a simplifying assumption here that the contractee pays only after the contractor has delivered the promised service. Many contracts require the contractee to pay in advance or make a deposit. These contracts would require slightly different rules here.

11. $\neg$ Cause $(\mathrm{CO}, \varepsilon), \neg$ Cause $(\mathrm{CE}, \varepsilon)$ are assumptions since common sense assumes a person does not do bad things unless proven contrary.

12. It is not difficult to see that the extension is also grounded and stable.

\section{References}

Ashley, K.D. (1991), 'Reasoning with Cases and Hypotheticals in HYPO', International Journal of Man-Machine Studies, 34(6), 753-796.

Atkinson, K., and Bench-Capon, T.J.M. (2005), 'Legal Case-based Reasoning as Practical Reasoning', Artificial Intelligence and Law, 13(1), 93-131.

Atkinson, K., and Bench-Capon, T. (2008), 'Abstract Argumentation Scheme Frameworks', in AIMSA '08: Proceedings of the 13th International Conference on Arificial Intelligence, Berlin, Heidelberg: Springer-Verlag, pp. 220-234.

Bench-Capon, T.J.M., and Modgil, S. (2009). 'Case Law in Extended Argumentation Frameworks', in Proceedings of the 12th International Conference on Artificial Intelligence and Law, Barcelona, Spain: ACM Press, pp. 118-127.

Bench-Capon, T., and Prakken, H. (2008), 'Introducing the Logic and Law Corner', Journal of Logic and Computation, 18(1), 1-12.

Bench-Capon, T.J.M., and Sartor, G. (2003), 'A Model of Legal Reasoning with Cases Incorporating Theories and Values', Artificial Intelligence, 150(1-2), 97-143.

Bench-Capon, T.J.M., Atkinson, K., and Chorley, A. (2005), 'Persuasion and Value in Legal Argument', Journal of Logic and Computation, 15(6), 1075-1097.

Berman, D.H., and Hafner, C.D. (1993). Representing Teleological Structure in Case-based Legal Reasoning: The Missing Link, in ICAIL '93: Proceedings of the 4th International Conference on Artificial Intelligence and Law, New York, NY: ACM, pp. 50-59.

Bex, F., Prakken, H., Reed, C., and Walton, D. (2003), 'Towards a Formal Account of Reasoning about Evidence: Argumentation Schemes and Generalisations', Artificial Intelligence and Law, 11(2), 125-165.

Bex, F., Van den Braak, S., Van Oostendorp, H., Prakken, H., Verheij, B., and Vreeswijk, G. (2007), 'Sensemaking Software for Crime Investigation: How to Combine Stories and Arguments?', Law, Probability and Risk, 6(1-4), 145-168.

Bondarenko, A., Dung, P.M., Kowalski, R.A., and Toni, F. (1997), 'An Abstract Argumentation Theoretic Approach to Default Reasoning', Artificial Intelligence, 93(1-2), 63-101.

Bruninghaus, K.D.A.S. (2003), 'Predicting Outcomes of Case-based Legal Arguments', in ICAIL 2003, NewYork: ACM Press.

Dung, P.M. (1993), 'Logic Programming as Dialog-game', Technical Report, AIT.

Dung, P.M. (1995), 'On the Acceptability of Arguments and its Fundamental Role in Nonmonotonic Reasoning, Logic Programming, and n-Person Games', Artificial Intelligence, 77(2), 321-257.

Dung, P.M., and Thang, P.M. (2008). 'Modular Argumentation for Modelling Legal Doctrines in Common Law of Contract', in Proceedings of the 21st Annual Conference, JURIX 2008, Volume 189 of Frontiers in Artificial Intelligence and Applications, Florence, Italy: IOS Press, pp. 108-117.

Dung, P.M., and Thang, P.M. (2009), 'Modular Argumentation for Modelling Legal Doctrines in Common Law of Contract', Artificial Intelligence and Law, 17(3), 167-182.

Dung, P.M., and Thang, P.M. (2009), An Unified Framework for Dialectical Proof Procedures in Argumentation, in Proceedings of Twenty-first International Joint Conference on Artificial Intelligence (IJCAI-09), Pasadena, California: Springer Verlag.

Dung, P.M., Kowalski, R., and Toni, F. (2006), 'Dialectic Proof Procedures for Assumption-based, Admissible Argumentation', Artificial Intelligence, 170(2), 114-159.

Dung, P.M., Kowalski Robert, A., and Toni, F. (2009), 'Assumption-based Argumentation', in Argumentation in AI, ISBN: 9780387981963, New York: Springer-Verlag.

Dung, P.M., Mancarella, P., and Toni, F. (2007), 'Computing Ideal Skeptical Argumentation', Artificial Intelligence, 171(10-15), 642-674. 
Dung, P.M., Thang, P.M., and Hung, N.D. (2009), 'Modular Argumentation for Modelling Legal Doctrines of Performance Relief', in ICAIL, 128-136.

Farnsworth, E.A., Young, W.F., and Sanger, C. (2001), Contracts: Cases and Materials (6th ed.), ISBN: 1587780577), New York, USA: Foundation Press.

Farrell, A.D.H., Sergot, M.J., Sallé, M., and Bartolini, C. (2005), 'Using the Event Calculus for Tracking the Normative State of Contracts', International Journal of Cooperative Information Systems, 14(2-3), 99-129.

Freitel, G. (2004), Frustration and Force Majeure (2nd ed.). London, UK: Sweet and Maxell Press.

Gaertner, D., and Toni, F. (2008), 'Hybrid Argumentation and its Properties', in COMMA, 183-195.

García, A.J., and Simari, G.R. (2004), 'Defeasible Logic Programming: An Argumentative Approach', TPLP, 4(1-2), 95-138.

Gardner, A.v.d.L. (1987), An Artificial Intelligence Approach to Legal Reasoning, Mit Press Series of Artificial Intelligence and Legal Reasoning, Cambridge, MA: MIT Press.

Gordon, T.F. (1994), 'The Pleadings Game: An Exercise in Computational Dialectics', Artificial Intelligence and Law, 2(4), 239-292.

Gordon, T.F., Prakken, H., and Walton, D. (2007), 'The Carneades Model of Argument and Burden of Proof', Artificial Intelligence, 171(10-15), 875-896.

Governatori, G., and Milosevic, Z. (2006), 'A Formal Analysis of a Business Contract Language', International Journal of Cooperative Information Systems, 15(4), 659-685.

Lewison, K. (2004), The Interpretation of Contracts, London, UK: Sweet \& Maxell.

McCarty, L.T. (1995). An Implementation of Eisner v. Macomber, in ICAIL '95: Proceedings of the 5th International Conference on Artificial Intelligence and Law, New York, NY: ACM, pp. 276-286.

McKendrick, E. (2005), Contract Law: Text, Cases and Materials, Oxford, UK: Oxford University Press.

McMeel, G. (2007), The Contruction of Contracts, ISBN: 9780199277933, Oxford, UK: Oxford University Press.

Poole, D. (2001), 'Logical Argumentation, Abduction and Bayesian Decision Theory: A Bayesian Approach to Logical Arguments and it's Application to Legal Evidential Reasoning', Cardozo Law Review, 22(5-6), 1733-1746.

Posner, R.A. (2007), Economic Analysis of Law, New York, USA: Wolters Kluwer Law and Business Press.

Prakken, H. (2002), 'An Exercise in Formalising Teleological Case-based Reasoning', Artificial Intelligence and Law, 10(1-3), 113-133.

Prakken, H. (2006), 'Formal Systems for Persuasion Dialogue', The Knowledge Engineering Review, 1, $163-188$.

Prakken, H., and Sartor, G. (1996), 'A Dialectical Model of Assessing Conicting Arguments in Legal Reasoning', Artificial Intelligence and Law, 4(3-4), 331-368.

Prakken, H., and Sartor, G. (1998), 'Modelling Reasoning with Precedents in a Formal Dialogue Game', Artificial Intelligence and Law, 6(2-4), 231-287.

Rahwan, I., and Simari, G. (eds.) (2009), Argumentation in Artificial Intelligence, New York, USA: Springer-Verlag.

Rissland, E., and Skalak, D. (1991), 'Cabaret: Rule Interpretation in a Hybrid Architecture', International Journal of Man-Machine Studies Archive, 34(6), 839-887.

Roth, B., and Verheij, B. (2004), 'Cases and Dialectical Arguments - An Approach to Case-based Reasoning', in OTM Workshops, volume 3292 of Lecture Notes in Computer Science, New York, USA: Springer, pp. 634-651.

Samuel, G. (2000), Source Book on Obligations and Legal Remedies, London, UK: Cavendish Publishing Limited.

Sartor, G. (2002), 'Teleological Arguments and Theory-based Dialectics', Artificial Intelligence and Law, 10(1), 95-112.

Steven, J.B., and Melvin, A.E. (2007), Contract Law: Selected Source Materials, New York, USA: Foundation Press.

Verheij, B. (2003), 'Dialectical Argumentation with Argumentation Schemes: An Approach to Legal Logic', Artificial Intelligence and Law, 11(2-3), 167-195.

Walton, D. (1996), Argumentation Schemes for Presumptive Reasoning, ISBN: 080582071X DDC: 168 LCC: BC183 (alk. paper ed.). Mahwah, NJ: LEA.

Yoshino, H. (1995), 'The Systematization of Legal Meta-inference', in ICAIL, 266-275.

Yoshino, H. (1998), 'Logical Structure of Contract Law System - for Constructing a Knowledge Base of the United Nations Convention on Contracts for the International Sale of Goods', JACIII, 2(1), 2-11. 